\title{
DETERMINANTS OF TECHNOLOGY ADOPTION AMONG MALAYSIAN SMES: AN IDT PERSPECTIVE
}

\author{
Thurasamy Ramayah', Osman Mohamad², Azizah Omar³, Malliga \\ Marimuthu ${ }^{4}$ and Jasmine Yeap Ai Leen ${ }^{5}$ \\ ${ }^{1,3,4-5}$ School of Management ${ }^{1}$,Universiti Sains Malaysia \\ 11800 USM, Penang \\ ${ }^{2}$ Graduate School of Management, Multimedia University \\ 63100 Cyberjaya, Selangor \\ Corresponding author : ramayah@usm.my¹
}

\begin{abstract}
Traditional competitive advantages such as raw material availability, inexpensive labour and proximity to local markets are fast losing their importance to other factors such as technology adoption. In order to survive, it is imperative that organizations incorporate technology into their daily operations. Still, technological adoption and information and communications technology penetration among the Malaysian SME industry is yet to reach a much desired level. Hence, this paper aims to reveal the factors that drive technology adoption among SMEs in Malaysia using the perceived innovation characteristics outlined in the Innovation Diffusion Theory (IDT). Data was gathered from manufacturing and manufacturing-related services; SMEs scattered throughout the country and analyzed using the partial least squares technique. The analysis revealed that innovation characteristics such as perceived relative advantage, observability and image are positively-related to the adoption of a technology while compatibility and ease of use do not influence adoption. Interestingly, though trialability was found to have a significant impact on adoption, its effect turned out to be a negative one instead of a positive hypothesized relationship. The findings are further discussed and elaborated.
\end{abstract}

Keywords: Small and medium enterprises, SMEs, technology adoption, innovation diffusion theory, partial least squares. 


\section{INTRODUCTION}

It is a highly acknowledged fact that in order to survive, organizations have to constantly improve their way of doing business (Teece, 2010). Once thoughtof as crucial determinants in the success of businesses, traditional competitive advantages such as raw material availability, inexpensive labour and proximity to local markets are fast losing their importance (Da Silveira, 2001) to other factors such as technology adoption. Basically, technology can be a powerful means to gain competitive advantage for two primary functions: 1) for supporting the business processes to produce products or services which are cost effective; and 2) for time saving through the improvement of productive yields (Hussain, \& Phatak, 2002). For developing countries such as Malaysia, technology adoption among its small and medium enterprises (SMEs) has become an important issue because of their significant contribution to the country's economic development (Abdullah, 2002). The ability of SMEs to adopt and utilize technology will enable them to be more flexible, dynamic and responsive. This is especially so for manufacturing SMEs, whereby the adoption of Advanced Manufacturing Technology (AMT), computer-based production systems, computer-based administration systems will enhance their day-to-day operations, hence boosting their competitiveness and sustainability.

Since technology is beneficial to manufacturing companies, the Malaysian Government introduced policies and various incentives including financial assistance and technological infrastructure to accelerate technology adoption and diffusion among the Malaysian manufacturing SMEs. Still, technological adoption and information and communications technology penetration among the Malaysian SME industry have yet to reach a much desired level (Saleh, \& Ndubisi, 2006). In light of this predicament, there is a need for deeper understanding on the factors that propel technology adoption among SMEs. There have been various studies on the adoption of technology. The broad generalizations derived were that one ought to consider the 1) characteristics of the firm; 2) competitiveness and management strategies of the firm; 3) influences of internal and external parties on the adoption decision process; and 4) characteristics of the technology adopted (Lefebvre, Harvey, and Lefebvre, 1991) as well as 5) perceived benefits and 6) organizational readiness (Iacovou, Benbasat, \& Dexter, 1995). Despite all the studies conducted there is much room left for research in technology adoption among SMEs as most studies conducted have focused on a specific technology in question (e.g. EDI, e-commerce) without discussing the adoption of all types of technology collectively (i.e. hard and soft technology) among SMEs within the manufacturing context. Hence, the aim of this paper is to reveal the factors that drive technology adoption among manufacturing SMEs in a 
developing economy namely Malaysia. In particular, this study has focused on the characteristics of technology adopted because behaviours that are close in time, as reflected by adoption behaviour, are more likely to be affected by concrete, specific and context-dependent considerations (Arts, Frambach, \& Bijmolt, 2011), of which characteristics of a technology would serve as exemplar considerations. Furthermore, as a predictor of technology adoption, the characteristics of a technology are generally considered as the most significant factors in explaining the rate of adoption (Kendall et al., 2001).

\section{INNOVATION-DIFFUSION THEORY}

Since the late 1980s, research on technology adoption focusing on exploring the determinants of users' intentions to accept and use new technology have produced a number of theoretical models, among which innovation diffusion theory (IDT) is generally regarded as one of the most influential models . Based on Rogers' contributions to the field of innovation diffusion research, IDT proposes that it is the potential adopters' perceptions of an innovation's characteristics that impact the diffusion rate, not experts' predictions or assessments of the characteristics that matter (Rogers, 1983). He identified five general characteristics of innovations that numerous diffusion studies have shown to have consistently influenced adoption, namely:

Relative advantage - the degree to which an innovation is perceived as being better than its precursor;

Compatibility - the degree to which an innovation is perceived as being consistent with the existing values, needs and past experiences of potential adopters;

Complexity - the degree to which an innovation is perceived as being difficult to understand and use;

Observability - the degree to which the results of an innovation are observable to others;

Trialability - the degree to which an innovation may be experimented with before adoption.

Moore and Benbasat (1991) adapted the characteristics of innovations presented in Rogers (1983) in their research on measuring perceptions of information technology adoption and introduced several constructs that served as additional factors influencing adoption and use, which include: 
Results demonstrability - the tangibility of the results of using the innovation, including their observability and communicability.

Image - the degree to which use of an innovation is perceived to enhance one's image or status in one's social system;

Visibility - the degree to which one can see others using the system in the organization;

Voluntariness of use - the degree to which use of the innovation is perceived as being voluntary, or of free will.

Result demonstrability and visibility are two sub-components of observability that have been demonstrated empirically to be separate constructs (Moore \& Benbasat, 1991). According to Rogers (1983), adoption is a decision to make full use of an innovation as the best course of action whereas rejection is a decision not to adopt an available innovation. Rogers (1983) hypothesized that positive perception of the usage of innovation can result in the early use of this innovation while negative perception will lead to late use of this innovation. In this study, innovation(s) refer to technology such as Advanced Manufacturing Technology (AMT), computer-based production systems and computer-based administration systems that can help improve the operations of manufacturing and manufacturing-related services SMEs.

\section{RESEARCH MODEL AND HYPOTHESES}

Based on the IDT, this study proposed that the characteristics of innovations influence technology adoption among SMEs. All five characteristics identified in Rogers (1983) seminal work are used in this study as they are regarded to be highly relevant to examine the adoption of both soft and hard technology among SMEs. Given the amount of coverage technology in manufacturing has received in the popular press, image was duly included in this study. However, results demonstrability, visibility and voluntariness were excluded in this study. Results demonstrability was not used in this study as its operationalization bore much resemblance to observability. Moreover, as Moore and Benbasat (1991) have discovered in their research, results demonstrability is a subcomponent of observability. Considering that the adoption of technology among the SMEs remains very much an individual choice and is not likely to be mandated by the Government (though the Government highly encourages its usage), voluntariness would be unlikely to show any variability, and is best excluded in this study. In addition, unlike personal technological gadgets such as mobile phones or digital cameras that are carried around by users, the 
use of hard and soft technology is mostly confined within the perimeters of manufacturing plants and offices. Its relatively lower visibility makes it rather inappropriate to be included in this study.

\section{Perceived relative advantage}

Relative advantage refers to the benefits of the innovation over alternative offerings (Arts et al., 2011). Studies have consistently proved that a positive relationship exists between relative advantage and innovation adoption (Agarwal, \& Prasad, 1997; Kwon, \& Zmud, 1987; Tornatzky, \& Klein, 1982; Van Slyke et al., 2002). For instance, SMEs would be willing and able to incorporate the use of automated production lines into their operations should they be shown the benefits it has over manual labour. The more SMEs perceive a technology to be superior over their conventional way of getting things done, the higher the likelihood they will adopt that technology. Therefore, it is hypothesized that:

H1: Perceived relative advantage of a technology positively affects SMEs' adoption of the technology.

\section{Compatibility}

Compatibility reflects the degree to which the innovation matches the potential adopter's needs and values and is therefore an important aspect of the innovation's desirability to the adopter (Arts et al., 2011). Tornatzky and Klein (1982) discovered that an innovation is more likely to be adopted if it is attuned with individuals' job responsibilities and value systems. Other researchers such as Kwon and Zmud (1987), Benham and Raymond (1996) and Tan and Teo (2000) also believed that the more an innovation is recognized as compatible with the existing values, needs and past experiences of potential adopters, the more it would be adopted. In the case of SMEs, the more SMEs recognize that both soft and hard technology are fit into their organizations' values, beliefs and business needs, the more likely they would be to adopt the technology. For this reason, it is posited that:

$\mathrm{H} 2$ : Compatibility of a technology positively affects SMEs' adoption of the technology.

\section{Complexity / Ease of use}

Complexity, i.e. the degree to which an innovation is seen by the potential adopter as being relatively difficult to use and understand, has been shown to hinder adoption (Rogers, 1983; Tornatzky, \& Klein, 1982). The opposite 
also holds true whereby if an innovation is perceived by the potential adopter as being relatively easy to use and understand, the higher the possibility of it being adopted. Rogers (1983) noted that the adoption of personal computers increased when they became user friendly. Similarly, organizations including SMEs turned to the Internet and electronic mail when they discovered how much the technology facilitated their business operations. For this study, ease of use, that is the other side of complexity, is used to show a positive relationship between an innovation's characteristic and adoption instead of a negative one. Based on the aforementioned literature, the following hypothesis was developed:

H3: A technology's ease of use positively affects SMEs' adoption of the technology.

\section{Trialability}

Trialability enables the potential adopter to see how the innovation works. Through triability, the potential adopter is able to assess the extent of change required when adopting the innovation. In this respect, Meuter, Bitner, Ostrom, \& Brown (2005) found that trialability enhances consumer readiness, such that it helps the potential adopter to develop confidence in using the innovation thereby affecting the feasibility of them using the innovation. Being allowed to experiment with a technology, SMEs would feel more comfortable to use the technology for their daily operations and are more likely to adopt the technology. Hence, this leads to the following hypothesis:

H4: Trialability of a technology positively affects SMEs' adoption of the technology.

\section{Observability}

According to Rogers (1996), observability is the ability to see the beneficial results of an innovation. Observability may help to show positive output that increases the adopter's motivation to receive the innovation's rewards (Meuter et al., 2005). Such higher desirability is likely to stimulate the adoption of the innovation. If SMEs can perceive the benefits of technology adoption, it is very likely that they will adopt it. As they observe the success of technology initiatives taken by other companies, SMEs would be drawn to adopt the same technology initiatives. For this reason, it is believed that:

H5: Observability of a technology positively affects SMEs' adoption of the technology. 


\section{Image}

The role of perceived image has been studied in information technologybased innovation adoption (Agarwal, \& Prasad, 1997; Van Slyke, Lou, \& Day, 2002), although there has been little empirical support for its relationship to use intentions. However, the growing use of technology and the amount of coverage technology in the manufacturing industry has received in the popular press suggests that an innovation's image-enhancing impacts may well be an important factor that decides the adoption of the innovation. For the SMEs, the adoption of technology would very likely enhance their image and elevate their status not only among the SME business circle but also among the society as an advanced, modern and efficient company. Thus, it is suspected that:

H6: A technology's image-enhancing impact positively affects SMEs'adoption of the technology.

\section{METHODOLOGY}

\section{Sample}

Manufacturing is an undeniably important sector for many countries due to its significant contribution to the economy and creation of enormous job prospects. In Malaysia, it is the largest contributor to the national economy (BNM, 2011). It also contributes indirectly to the economy through synergistic relationships with other economic sectors such as trading, finance, transportation and services (Islam, \& Karim, 2011). Hence, data was gathered from manufacturing and manufacturing-related services SMEs scattered throughout the country. The SMEs sampled were involved in various industries such as food and beverages, electrical and electronics, wood and wood products, rubber and plastic products, machinery and equipment, transportation, textile and apparels, chemical and chemical products, metallic as well as non-metallic mineral products etc.

Out of the 1500 surveys sent out by mail, only 544 were completed and returned, resulting in a response rate of $36.26 \%$. The surveys were completed by the owners/managers of the manufacturing and manufacturing-related services SMEs. In SMEs, the entrepreneur-owner or manager typically plays an active role in managing the business. They are usually involved in all decision-making within the organization including adoption decisions involving technological innovations, thus making them the most appropriate representatives of their companies to answer the survey. 
The SME owners/managers surveyed comprised more of male owners/ managers $(59.9 \%)$ than female owners/managers $(40.1 \%)$. The majority of them were young, and aged between 26 and 35 (41.2\%), and 36 and 45 (34.2\%). They were mostly Chinese (57.0\%), followed by Malays (37.1\%), Indians (4.4\%) and other ethnicities (1.5\%). All of them had some form of educational qualification with bachelor's degrees (49.6\%) and diplomas (21.7\%) being the most popular. Only a handful had a master's $(8.8 \%)$ or $\mathrm{PhD}$ degree $(0.7 \%)$ as well as other qualifications $(19.1 \%)$.

A large percentage of the SMEs were registered as private limited companies $(57.7 \%)$, while the rest were sole proprietors $(28.3 \%)$, partnerships $(10.3 \%)$ or other types of business (3.7\%). Half of the SMEs $(51.1 \%)$ had been in operation between one and 10 years while the other half $(48.9 \%)$ had already been in the industry for more than 10 years. The majority of the SMEs (53.3\%) had 1 to 50 employees while another $46.7 \%$ had more than 50 employees. Most of them $(71.7 \%)$ operated domestically with no foreign exporting activities. The use of technology was apparent within the SMEs as a large percentage of them $(86.8 \%)$ were computerized.

\section{Survey instrument}

The items on the perceived innovation characteristics were adapted from Moore and Benbasat (1991). This study only adopted six out of the nine characteristics (i.e. perceived relative advantage, compatibility, ease-of-use, trialability, observability and image) which were deemed most suitable for the context of this study. The items utilized a 7-point Likert scale ranging from $1=$ strongly disagree to $7=$ strongly agree. On the other hand, the list of technology types adopted by SMEs was derived from interviews conducted with five -owners/managers of manufacturing and manufacturing-related services SMEs. The selection of these five respondents were done using a purposive sampling method whereby the criteria used was that they must be involved in technology implementation in their respective companies with at least five years' experience. The interviews resulted in a list of 46 types of technology classified as either hard technology or soft technology. For hard technology, the orchestration of technology is embedded in a device. In short, it involves mostly machinery and equipment. There were 23 items measuring this component of technology. Some examples of items include CAD/CAM - computer-aided design, computer-aided manufacturing, numerical control machines, automated production line, pick and place robots, and flexible manufacturing system. In contrast, soft technology involves an active orchestration of phenomena by people. This type of technology is mostly 
in the form of programs/philosophies/behavioural approaches (Aggarwal, 1995). There were 23 items measuring this component of technology, which includes JIT (just-in-time), TQM (total quality management), CRM (customer relationship management) and forecasting or sales analysis software. Respondents were asked if they adopted any of the hard and/or soft technology in their company, using a scale of $0=$ no (do not adopt) and $1=$ yes (adopt).

\section{ANALYSIS AND RESULTS}

Partial least squares (PLS) technique through the SmartPLS 2.0 software (Ringle, Wendle \& Will, 2005) was applied to analyse the data collected. Components-based structural equation modeling (SEM) such as PLS is rapidly becoming a widely-used alternative to covariance-based SEM. Similar to covariance-based SEM, PLS can assess the psychometric properties of the measurement model and estimate the parameters of the structural model (AlGahtani, Hubona, \& Wang, 2007). However, unlike covariance-based SEM which focuses on achieving the best fit for the research model, componentsbased SEM aims to maximize the explained variance of the endogenous variables (Gefen, Straub, \& Boudreau, 2000). It is also far less restrictive in its distributional assumptions (Fornell, \& Cha, 1994) and accommodates both reflective and formative measures in its analysis of the research model in question. Following the suggestion of Anderson and Gerbing (1988), a two-step analysis approach was adopted in analyzing the data, whereby the measurement model was first estimated prior to assessing the structural model. In addition, the bootstrapping method (200 resamples) was done to determine the significance levels for loadings, weights and path coefficients (Chin, 1998).

\section{Measurement model}

The measurement model consists of relationships among the latent variables and their (item) indicators. It is necessary to first establish construct validity for the measurement model before assessing the structural model for hypothesis testing. Construct validity concerns the extent to which the indicators reflect their underlying constructs (latent variables). Items in the measurement model need to demonstrate sufficient convergent and discriminant validity as a condition for establishing construct validity. As recommended by Hair, Black, Babin, \& Anderson (2006), factor loadings, composite reliability and average variance extracted (AVE) were used to assess convergent validity. Table 1 lists the indicator loadings/weights, reliabilities and AVE for all the items listed in the model. 
Table 1

\section{Convergent Validity}

\begin{tabular}{|c|c|c|c|c|c|}
\hline Item indicators & $\begin{array}{l}\text { Type of } \\
\text { measure }\end{array}$ & $\begin{array}{c}\text { Item loadings/ } \\
\text { weights }\end{array}$ & $\begin{array}{l}\text { Composite } \\
\text { reliability }\end{array}$ & $\begin{array}{l}\text { Cronbach } \\
\text { alpha }\end{array}$ & AVE \\
\hline \multicolumn{6}{|c|}{ Perceived Relative Advantage } \\
\hline PRA1 & \multirow{4}{*}{ Reflective } & 0.760 & \multirow{4}{*}{0.907} & \multirow{4}{*}{0.863} & \multirow{4}{*}{0.71} \\
\hline PRA2 & & 0.851 & & & \\
\hline PRA3 & & 0.888 & & & \\
\hline PRA4 & & 0.866 & & & \\
\hline \multicolumn{6}{|l|}{ Compatibility } \\
\hline COM1 & \multirow{3}{*}{ Reflective } & 0.894 & \multirow{3}{*}{0.844} & \multirow{3}{*}{0.741} & \multirow{3}{*}{0.647} \\
\hline COM2 & & 0.654 & & & \\
\hline COM3 & & 0.846 & & & \\
\hline \multicolumn{6}{|l|}{ Ease of Use } \\
\hline EOU1 & \multirow{4}{*}{ Reflective } & 0.556 & \multirow{4}{*}{0.831} & \multirow{4}{*}{0.762} & \multirow{4}{*}{0.557} \\
\hline EOU2 & & 0.757 & & & \\
\hline EOU3 & & 0.772 & & & \\
\hline EOU4 & & 0.866 & & & \\
\hline \multicolumn{6}{|l|}{ Trialability } \\
\hline TRI1 & \multirow{3}{*}{ Reflective } & 0.893 & \multirow{4}{*}{0.834} & \multirow{4}{*}{0.609} & \multirow{3}{*}{0.715} \\
\hline TRI2 & & 0.796 & & & \\
\hline TRI $3 \uparrow$ & & - & & & \\
\hline \multicolumn{4}{|l|}{ Observability } & & \\
\hline OBS1 & \multirow{4}{*}{ Reflective } & 0.841 & \multirow{4}{*}{0.900} & \multirow{4}{*}{0.852} & \multirow{4}{*}{0.692} \\
\hline OBS2 & & 0.843 & & & \\
\hline OBS3 & & 0.807 & & & \\
\hline OBS4 & & 0.835 & & & \\
\hline \multicolumn{6}{|l|}{ Image } \\
\hline IMA1 & Reflective & 0.935 & 0.926 & 0.840 & 0.862 \\
\hline IMA2 & & 0.922 & & & \\
\hline \multicolumn{6}{|l|}{ Adoption } \\
\hline HTA* & Formative & -1.224 & - & - & - \\
\hline STA* & & 1.740 & & & \\
\hline
\end{tabular}

$\S$ Loadings are for reflective items while weights are for formative items

$\dagger$ Item dropped as its loading did not exceed the cut-off requirement of 0.50 set by Hair et al. (2006).

*The items are summated scores of adoption according to their respective classification, HTA (hard technology adoption) and STA (soft technology adoption).

The loadings of all reflective indicators surpassed the required cut-off level of 0.60 as suggested by Bagozzi and Yi (1988) except for item EOU1. Nevertheless, this item was not dropped from the analysis as it was still able 
to surpass at least the minimum value of 0.50 As suggested by Hair et al. (2006). On this note, item TRI3 was dropped from the model as it failed to meet the 0.50 minimum threshold value. The composite reliability values for all reflective constructs exceeded the threshold value of 0.70 recommended by Hair et al., (2006) while the AVEs for each construct were over the recommended value of 0.50 as suggested by Fornell and Larcker (1981). In short, convergent validity was established.

While indicator loadings, reliabilities and AVE are used to assess convergent validity for reflective constructs, they are not appropriate or meaningful for formative constructs (Bollen, \& Lennox, 1991; Diamantopoulos, \& Winklhofer, 2001). In the presence of a measurement model which has formative constructs, the focus should be on the weights of each measure rather than the indicator loadings (Petter, Straub, \& Rai, 2007). The t-values of each item weight should be significant in order to achieve indicator validity, a condition that refers to the importance of each individual indicator of the related formative construct (Andreev, Heart, Maoz, \& Pliskin, 2009; MacKenzie, Podsakoff \& Jarvis, 2005). For this study, adoption was considered as a construct with formative indicators because both indicators, i.e. hard technology adoption and soft technology adoption exclusively define and form the essence underlying the technology adoption construct. From the bootstrapping procedure, the weights of both hard technology adoption $(t=2.327, p<0.05)$ and soft technology adoption $(t=3.659, p<0.01)$ were found to be significant, signifying sufficient indicator validity had been achieved.

In contrast to convergent validity, discriminant validity can be tested for both the reflective and formative constructs. Discriminant validity is the degree to which the measures of different constructs are distinct from one another and is assessed by comparing the correlations between constructs with the square root of the AVE for a construct (Fornell, \& Larcker, 1981). Based on Table 2, the elements in the matrix diagonals, representing the square root of the AVEs, are greater in all cases than the off-diagonal elements in their corresponding row and column, indicating discriminant validity had been achieved.

Table 2

Discriminant Validity

\begin{tabular}{lccccccc}
\hline Constructs & PRA & COM & EOU & TRI & OBS & IMA & ADO \\
\hline $\begin{array}{l}\text { Perceived Relative } \\
\text { Advantage (PRA) }\end{array}$ & $\mathbf{0 . 8 4 3}$ & & & & & & \\
Compatibility (COM) & 0.558 & $\mathbf{0 . 8 0 4}$ & & & & & \\
\hline
\end{tabular}

(continued) 


\begin{tabular}{lccccccc}
\hline Constructs & PRA & COM & EOU & TRI & OBS & IMA & ADO \\
\hline Ease of Use (EOU) & -0.390 & -0.532 & $\mathbf{0 . 7 4 6}$ & & & & \\
Trialability (TRI) & 0.267 & 0.376 & -0.253 & $\mathbf{0 . 8 4 6}$ & & & \\
Observability (OBS) & 0.596 & 0.553 & -0.515 & 0.280 & $\mathbf{0 . 8 3 2}$ & & \\
Image (IMA) & 0.328 & 0.3529 & -0.293 & 0.202 & 0.422 & $\mathbf{0 . 9 2 8}$ & \\
Adoption (ADO) & 0.289 & 0.190 & -0.182 & -0.084 & 0.258 & 0.214 & - \\
\hline
\end{tabular}

Note: 1) Diagonals represent the square root of the AVEs while the off-diagonal entries represent the correlations between constructs; 2) N/A - square root of the AVE is not available for formative constructs.

\section{Structural model}

Following the assessment of the measurement model, the structural model was then analyzed. The structural model comprises the hypothesized relationship between exogenous and endogenous variables in the model. Table 3 shows the results for the structural model. The explanatory power of the estimated model can be assessed by observing the $\mathrm{R}^{2}$ of the endogenous constructs. The $\mathrm{R}^{2}$ value obtained from the analysis was 0.146 , indicating that $14.6 \%$ of variance in adoption can be explained by all the exogenous variables in the model. Perceived relative advantage $(b=0.213, p<0.01)$, trialability $(b=-0.217$, $\mathrm{p}<0.01)$, observability $(b=0.098, p<0.10)$ and image $(b=0.121, p<0.10)$ were found to have a significant effect on adoption. Although trialability was found to be significantly-related to adoption, the direction of its relationship was negative instead of its hypothesized positive relationship. Therefore, $\mathrm{H} 4$ was not supported despite the significance of the relationship. Only H1, H5 and H6 were supported.

Table 3

Results of the Structural Model

\begin{tabular}{llclll}
\hline Hypotheses & Relationship & Coefficient & t-value & $\mathrm{R}^{2}$ & \multicolumn{1}{c}{$\begin{array}{c}\text { Hypotheses } \\
\text { results }\end{array}$} \\
\hline H1 & PRA $\rightarrow$ ADO & 0.213 & $2.938^{* *}$ & & Supported \\
H2 & COM $\rightarrow$ ADO & 0.027 & 0.430 & & Not supported \\
H3 & EOU $\rightarrow$ ADO & -0.052 & 0.594 & \multirow{2}{*}{0.146} & Not supported \\
H4 & TRI $\rightarrow$ ADO & -0.217 & $2.125^{* *}$ & & Not supported \\
H5 & OBS $\rightarrow$ ADO & 0.098 & $1.557^{*}$ & & Supported \\
H6 & IMA $\rightarrow$ ADO & 0.121 & $1.608^{*}$ & & Supported \\
\hline
\end{tabular}

Note: ${ }^{*} \mathrm{p}<0.10 ;{ }^{* *} \mathrm{p}<0.01$ 


\section{DISCUSSION AND CONCLUSION}

This paper aimed to provide some insights into the perceived innovation characteristics that propel the adoption of technology among SMEs in Malaysia. In particular, this study investigated the impact of six characteristics as proposed by Rogers (1983) as well as Moore and Benbasat (1991) namely, perceived relative advantage, compatibility, ease of use, trialability, observability and image, on the SMEs technology adoption. The findings revealed that out of the six characteristics, only three were found to exhibit a positive effect on adoption. As hypothesized, perceived relative advantage and observability positively affect technology adoption. Both perceived relative advantage and observability share a common underlying theme whereby both relate to the benefits that are brought upon through the adoption of an innovation. When SMEs perceive a technology to supersede conventional methods of getting things done and are able to observe major, positive results (e.g. increase in productivity, improvement in sales growth, higher customer satisfaction and retention) from using the technology, they would be more likely to be driven to adopt it. Apart from its apparent benefits, technology adoption is very much related to a company's image. Being suppliers to the larger, (multinational) companies, SMEs cannot afford to be reclusive and not keep up with the changes over time whereby technology has become integrated in every aspect of work and living. Instead they should embrace technology because it helps to elevate the status of the company within the business realm, signifying that the company is an advanced, modern and efficient one. Such enhancement in the company's image is crucial in helping companies to expand internationally, thus enabling them to compete as a global player in major markets. Therefore, policy makers or any other parties for that matter who aspire to incorporate technology adoption among SMEs should definitely consider using the perceived relative advantage, observability and image enhancement characteristics of a technology in their adoption.

In stark contrast to the three aforementioned characteristics, ease of use and compatibility did not exhibit any significant impact on technology adoption. Perhaps what can be surmised from such findings is that as long as technology is shown to improve SMEs' manufacturing operations, services and most importantly business performance in every major way, this would far override any issues of complexity or incompatibility. A technology's complexity may be viewed as a challenge, but not a barrier to its adoption. Also, there would be times when some technology may not always be completely aligned with a company's founding beliefs or principles as well as policies. Yet, if the will to adopt a particular technology holds true and strong, companies would still gear themselves towards the adoption of technology. At the initial stages leading to adoption, it could be of no consequence whether or not a technology is 
attuned to the company's existing values, needs and past experiences because companies would probably find ways to work around those incompatibility issues. As for the trialability characteristic, in some cases, trial runs or experiments of a technology may result in unintentional time slippage or financial expenses. In other words, trialability of a technology may actually be more costly than letting the actual adoption and implementation of the technology run its full course. This may explain why trialability demonstrated a negative impact on adoption.

Presently this study only focused on the perceived innovation characteristics that drive technology adoption among SMEs in Malaysia. As an extension to this study, future researchers could design and conduct longitudinal studies that track the SMEs at two points in time, i.e. when it first adopts a technology and later after some time has passed to determine if the same technology is still being utilized. at this juncture of post-adoption, researchers can perhaps look into the factors that drive continuance in the usage of the technology. Nonetheless for now, this study has provided a glimpse of innovation characteristics that compel the adoption of both soft and hard technology among the SMEs in a developing country. It is hoped that the findings of this study will provide some useful insights for those who seek understanding on the adoption of technology among smaller companies from an IDT perspective.

\section{ACKNOWLEDGEMENT}

The authors would like to thank Universiti Sains Malaysia for funding this research under the grant 1001/PMGT/816069.

\section{REFERENCES}

Abdullah, M.A. (2002). An overview of the macroeconomic contribution of SMEs in Malaysia. In C. Harvie, \& B.C. Lee (Eds.), The role of SMEs in national economics in East Asia. United Kingdom: Edward Elgar.

Anderson, J.C., \& D.W. Gerbing. (1988). Structural equation modeling in practice: A review and recommended two-step approach. Psychological Bulletin, 103(3), 411-423.

Andreev, P., Heart, T., Maoz, H., \& N. Pliskin. (2009). Validating formative partial least squares (PLS) models: Methodological review and 
empirical illustration. Proceedings of the Thirtieth International Conference on Information Systems. Phoenix, Arizona.

Agarwal, R., \& J. Prasad. (1997). Role of innovation characteristics and perceived voluntariness in the acceptance of information technologies. Decision Sciences, 28(3), 557-582.

Aggarwal, S. (1995). Emerging hard and soft technologies: current status, issues and implementation problems. Omega: International Journal of Management Science, 23(3), 323-339.

Al-Gahtani, S. S., Hubona, G. S., \& Wang, J. (2007). Information technology (IT) in Saudi Arabia: Culture and the acceptance and use of IT. Information \& Management, 44(8), 681-691.

Arts, J.W.C., Frambach, R. T., \& Bijmolt, T.H.A. (2011). Generalizations on consumer innovation adoption: A meta-analysis on drivers of intention and behavior. International Journal of Research in Marketing, 28(2), 134-144.

Bagozzi, R. P., \& Yi, Y. (1988). On the evaluation of structural equation models. Journal of the Academy of Marketing Science, 16(1), 74-94.

Benham, H. C., \& Raymond, B. C. (1996). Information technology adoption: Evidence from a voice mail introduction. ACM SIGCPR Computer Personnel, 7(1), 3-25.

BNM. (2011). Economic and Financial Data for Malaysia. Bank Negara Malaysia. Retrieved from http://www.bnm.gov.my/index.php?ch=111

Bollen, K. A., \& Lennox, R. (1991). Conventional wisdom on measurement: A structural equation perspective. Psychological Bulletin, 110, 305-314.

Chin, W. W. (1998). The partial least squares approach to structural equation modeling. In G.A. Marcoulides, Mahwah (Eds.), Modern business research methods. NJ: Lawrence Erlbaum Associates.

Da Silveira, G. (2001). Innovation diffusion: R agenda for developing economies. Technovation, 21(12), 767-773.

Diamantopoulos, A., \& Winklhofer, H. M. (2001). Index construction with formative indicators: An alternative to scale development. Journal of Marketing Research, 38, 269-277. 
Fornell, C., \& J. Cha.(1994). Partial least squares. In R.P. Bagozzi, (Ed.), Advanced methods of marketing research (pp. 52-78). Oxford: Blackwell.

Fornell, C., \& Larcker, D. F. (1981). Evaluating structural equation models with unobservable variables and measurement error. Journal of Marketing Research, 18(1), 39-50.

Gefen, D., Straub, D. W., \& Boudreau, M. C. (2000). Structural equation modeling and regression: Guidelines for research practice. Communications of the AIS, 4(7), 1-79.

Hair, J.F., Black, W.C., Babin, B.J. \&., Anderson, R.E. (2006). Multivariate data analysis. Upper Saddle River, NJ: Pearson Prentice-Hall.

Hussain, Z., \& Phatak, R. D.(2002). A technology management perspectives on collaboration in the Indian automobile industry: A case study. Journal of Engineering Technology Management, 19(2), 167-201.

Iacovou, C. L., Benbasat, I., \& Dexter, A. (1995). Electronic data interchange and small organizations: Adoption and impact of technology. MIS Quarterly, 19(4), 466-485.

Islam, M., \& A. Karim. (2011). Manufacturing practices and performance: comparison among small-medium and large industries. International Journal of Quality \& Reliability Management, 28(1), 43-61.

Kendall, J. D., Tung, L. L., Chua, K. H., Ng, C. H. D., \& Tan, S.M. (2001). Receptivity of Singapore's SMEs to electronic commerce adoption. Journal of Strategic Information Systems, 10, 223-242.

Kwon, T. \&., R. W. Zmud, R. W.(1987). Unifying the fragmented models of information systems implementation. In R. J. Borland, Jr., \& Hirschman (Eds.),Critical issues in information systems (pp. 227-251). R.A. New York: John Wiley.

Lefebvre, L., Harvey, J., \& Lefebvre, E. (1991). Technological experience and the technology adoption decisions in small manufacturing firms. $R \& D$ Management, 21(3), 241-249.

Mackenzie, S. B., Podsakoff, P. M., \& Jarvis, C. B. (2005). The problem of measurement model misspecification in behavioral and organizational 
research and some recommended solutions. Journal of Applied Psychology, 90, 710-730.

Mehra, S., \& Agrawal, S. P. (2003). Total quality as a new global competitive strategy. International Journal of Quality \& Reliability Management, 20(9), 1009-1025.

Meuter, M. L., Bitner, M. J., Ostrom, A. L., \& Brown, S. W. (2005). Choosing among alternative service delivery modes: An investigation of customer trial of self-service technologies. Journal of Marketing, 69(2), 61-83.

Moore, G. C., \& Benbasat, I. (1991). Development of an instrument to measure the perceptions of adopting an information technology innovation. Information Systems Research, 2(3), 192-222.

Petter, S., Straub, D., \& A. Rai, (2007). Specifying formative constructs in information systems research. MIS Quarterly, 31(4), 623-656.

Rogers, E. M. (1983). Diffusion of innovations (3rd ed.). New York: Free Press.

Rogers, E. M. (1996). Communication technology: The new media society. New York: Free Press.

Ringle, C. M., Wende, S., \& Will, A. (2005). SmartPLS 2.0 (beta). Retrieved from www.smartpls.de.

Saleh, A.S., \& Ndubisi, N. O. (2006). An evaluation of SME development in Malaysia. International Review of Business Research Papers, 2(1), 1-14.

Tan, M., \& T. S . H. Teo . (2000). Factors influencing the adoption of internet banking. Journal of the Association for Information Systems, 1(5), 1-42.

Teece, D. J. (2010). Business models, business strategy and innovation. Long Range Planning, 43(2-3), 172-194.

Tornatzky, L. G., \& Klein. L. G. (1982). Innovation characteristics and innovation-implementation: A meta-analysis of findings. IEEE Transactions on Engineering Management, 29(1), 28-45.

Van Slyke, C., Lou, H., \& Day, J. (2002). The impact of perceived innovation characteristics on intention to use groupware. Information Resource Management Journal, 15(1), 5-12. 